\title{
The Gini Index: A Lens for Analyzing Inequality in an Interdisciplinary College Classroom
}

Jared Warner

Guttman Community College, jaredwarner4@gmail.com

Vivian Lim

Guttman Community College, vivian.liu@guttman.cuny.edu

\section{Recommended Citation}

Warner, Jared, and Vivian Lim. "The Gini Index: A Lens for Analyzing Inequality in an Interdisciplinary College Classroom." Numeracy 12, Iss. 1 (2019): Article 5. DOI: https://doi.org/10.5038/1936-4660.12.1.5 


\title{
The Gini Index: A Lens for Analyzing Inequality in an Interdisciplinary College Classroom
}

\begin{abstract}
The Gini index is one of the most commonly used indicators of income inequality, and its computation and interpretation require a thorough understanding of various quantitative literacy concepts. In this article, we describe a unit for an interdisciplinary quantitative literacy course at a community college that treats concepts of ratio and proportion, percentages, and mathematical modeling through an exploration of income inequality and the Gini index. The broader theme of the interdisciplinary course is immigration, so the unit also invites students to explore connections between the Gini index and immigration.

Employing in-class simulations, interactive online applets, and real-world data sets, the unit offers a variety of ways for students to encounter the quantitative literacy material through the lens of income inequality and immigration. Using both student and instructor reflections, we analyze the strengths and challenges of the unit through the lens of the culturally relevant mathematics pedagogy (CureMap) framework as developed by Rubel and Chu (2012).
\end{abstract}

\section{Keywords}

quantitative literacy, mathematics for social justice, Gini index, income inequality

\section{Creative Commons License}

\section{cc) (7) (8)}

This work is licensed under a Creative Commons Attribution-Noncommercial 4.0 License

\section{Cover Page Footnote}

Jared Warner and Vivian Lim are Assistant Professors of Mathematics at Guttman Community College. Jared enjoys the challenge of bringing mathematics to life for his students, and the creativity this challenge draws out of him. Vivian's background and research interest is in teaching mathematics for social justice; her goal is to challenge her students to view mathematics differently and to empower them to use mathematics to tackle the world's problems. 


\section{Introduction}

The Gini index is a mathematical tool that quantifies inequality in the distribution of a particular resource (income, wealth, energy, etc.) within a population (Gini 1912). Its direct function in measuring inequality presents a unique opportunity to teach mathematics for social justice. Teaching mathematics for social justice is an educational framework that aims to empower students to learn and use mathematics to uncover and address injustice in their lives, communities, and society (Gutstein 2006). The grounding of this approach can engage students who find abstract mathematics uninspiring but care deeply about issues of justice.

In a previous issue of Numeracy, Catalano et al. (2009) presented an example of how the Gini index can be used in a calculus class with the goal of incorporating social justice into the curriculum. In their work, they argue that teaching about the Gini index for social justice also presents rich opportunities to build students' quantitative literacy. The Gini index is a measure that relies on a model of income distribution, which opens up opportunities for students to engage in reasoning as they build and evaluate the mathematical model. Moreover, because the Gini index is a tool to evaluate inequality in real-world resource distributions, it is inherently embedded in a purposeful context and demands to be interpreted. Building and analyzing models of income distribution and interpreting the resulting Gini indices require reasoning about how the mathematics relates to the real world-what it means, what it represents, and what its implications are.

Although a study of the Gini index can employ calculus to measure inequality in resource distribution models, in this article we show how a simplified study of the Gini index centered on the concept of ratios can be used in the context of a quantitative literacy course. Our goals for this paper are threefold. First, we aim to share our curricular unit, framing it in relation to our objectives based on the course and institutional contexts and our own goals to promote social justice. Second, we provide our pedagogical rationale behind the unit's design, drawing on a framework for culturally relevant mathematics pedagogy (Rubel and Chu, 2012). Finally, we provide our reflections, questions, and insights about challenges and opportunities we encountered in the design and implementation of the unit.

\section{Institutional and Course Contexts}

The Gini index curricular unit we present in this paper was taught at Guttman Community College to three sections of an interdisciplinary, multi-component course called City Seminar. In this section, we provide a brief description of Guttman and City Seminar in order that our readers may fully understand how the unit is situated within our context. 
Guttman is a new community college located in Midtown Manhattan with a unique educational model. One of the cornerstones of our model is our First-Year Experience, in which students take most of their classes in a learning community with up to 30 of their peers. With the aim of increasing retention and improving graduation rates, each learning community progresses through a common set of core classes focused on the same themes. As of 2017, our student body was composed of mostly traditional students (98\% under 22 years old) and mostly minority students ( $92 \%$ non-white), with a majority qualifying to receive needbased financial aid $(71 \%){ }^{1}$

At the heart of the curriculum in our First-Year Experience is an interdisciplinary, multi-component course called City Seminar. Each City Seminar course is taught by multiple faculty members who collectively choose a theme with which to study New York City. While New York City remains the central object of study in all City Seminar courses, the theme of the course may change depending on the expertise and preference of the faculty members. One constant, though, is that the theme is related to some salient issue of justice in New York City (e.g., gentrification).

One of the three components of the course, called Critical Issue, is where the main socio-political topics surrounding the theme are addressed. The other two components are Reading \& Writing and Quantitative Reasoning, which serve as Guttman's mechanism for providing our first-year students with culturally relevant and embedded remediation. Quantitative Reasoning covers many skills typically found in a quantitative literacy course (ratio and proportion, percentages, mathematical modeling), but these skills are embedded in the study of the aforementioned City Seminar theme and bolstered by the interdisciplinary nature of the course.

The Gini index unit we describe in this paper was implemented in three different Quantitative Reasoning sections of a City Seminar course with the theme of immigration. All three sections were taught by Vivian Lim, one of the authors of this paper.

\section{Curriculum Description}

\section{Learning Objectives}

We designed the unit with two main learning objectives in mind, which bring together the goals of the Quantitative Reasoning course as well as our personal

\footnotetext{
${ }^{1}$ https://guttman.cuny.edu/about/fast-facts (Accessed June 28, 2018)
} 
goals to promote social justice. Upon completion of the unit, we wanted students to be able to apply a quantitative lens to:

1. describe and analyze inequality, and

2. evaluate effects of policies designed to address inequality.

In our context, the unit, as described below, addresses the learning objectives in very pointed ways. Specifically, the concepts of ratio and percent strongly shape the quantitative lens we invite students to consider throughout the unit because Guttman's Quantitative Reasoning courses emphasize these concepts. Furthermore, our unit invites students to describe and analyze income inequality (as measured by the Gini index) and to evaluate the fiscal policies of progressive taxation, universal basic income, and guaranteed minimum income.

\section{The Lorenz Curve and Gini Index}

Before proceeding with a description of the Gini index unit, we provide in this section a brief introduction to the Gini index as a measure of inequality. We also share some justification for our decision to build the unit around the Gini index given our institutional and course context and our learning objectives.

The Gini index was first introduced by Italian statistician Corrado Gini (Gini 1912) and is now used by the World Bank, the Central Intelligence Agency, and the United States Census Bureau to measure the inequality of a distribution of resources within populations as small as census tracts and as large as nations. Although the resource in question can be any quantifiable good (energy, food, health care, education), the Gini index is most commonly applied as a metric for income and wealth inequality. Here, we describe its derivation as applied to income distributions.

The Gini index is a number derived from the geometry of the Lorenz curve, $y$ $=L(x)$, where $L(x)$ is the percent of income earned by the lowest earning $x$ percent of the population. For example, if the lowest earning $20 \%$ of the population cumulatively make $5 \%$ of the income for a particular income distribution, then $L(20)=5$ (here and in what follows we use percentages instead of decimals). If income is distributed equally within a population, then for all $0 \leq x \leq 100, x$ percent of the population would make $x$ percent of the income (e.g., $50 \%$ of the population would together make $50 \%$ of the total income). As a mathematical function, this would be represented by $L(x)=x$, so we refer to the line $y=x$ as the "line of equality." For all other income distributions, we have that $L(x)<x$ for all $0<x<$ 100 so that the Lorenz curve lies below the line of equality. Notice then that the area of the region between the line of equality and the Lorenz curve is a measure of how far the income distribution strays from equality. The Gini index can be defined as the proportion of the area below the line of equality that lies above the Lorenz curve, which we will refer to here as the region of inequality (Fig. 1). There are 
many equivalent definitions of the Gini index, but we chose this definition for our students as it is consistent with our emphasis on ratio and percent. With this definition, the Gini index is always between zero and one, with values closer to one representing more unequal income distributions.

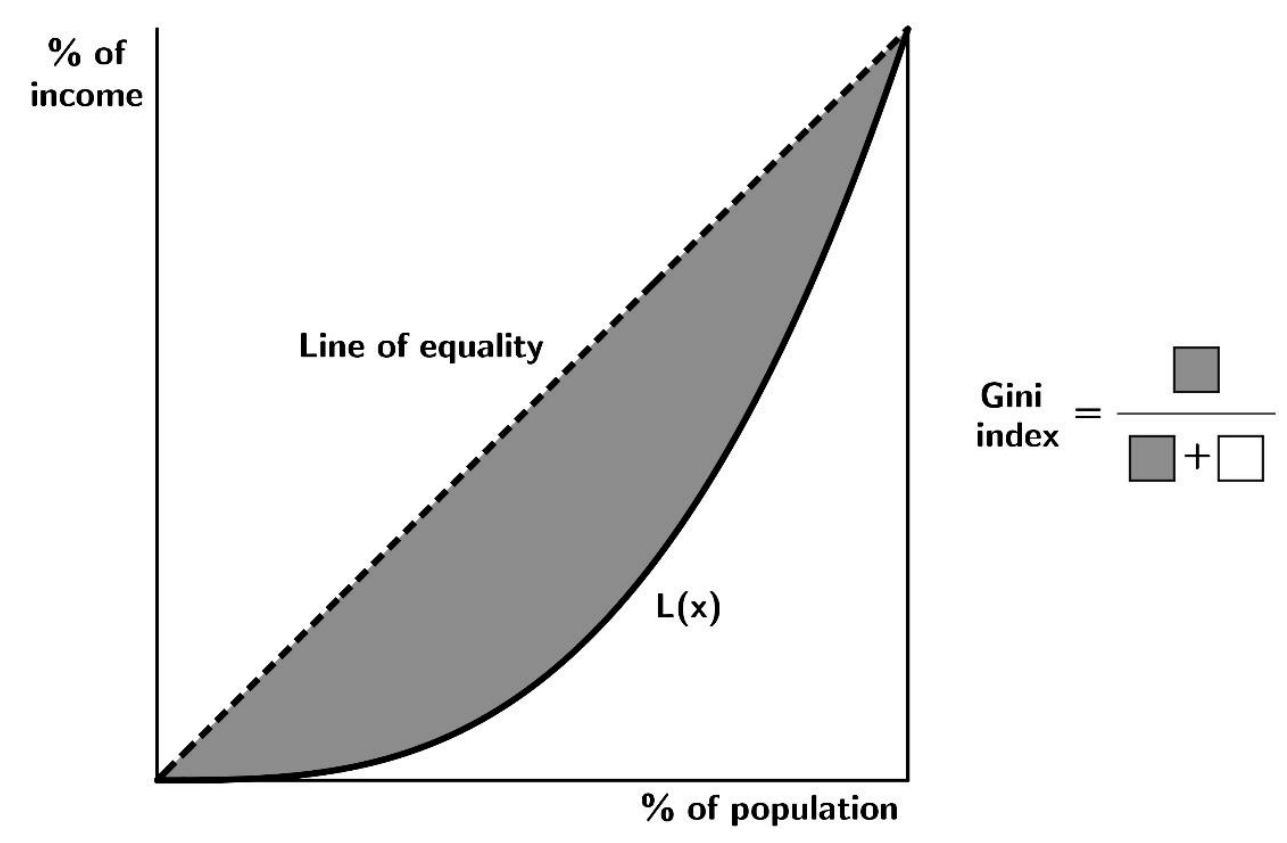

Figure 1. Lorenz curve and Gini index

To construct the exact Lorenz curve, one would need to know the income of each individual within a population. Since this information is rarely attainable for large populations, in practice the Lorenz curve can be approximated using information about the estimated income earned within particular brackets of society. For a very crude approximation, one can construct a piecewise-linear Lorenz curve using information about the mean household incomes within quintiles, and then compute the Gini index in the way described above from the approximated Lorenz curve (Fig. 2). It is this approach to approximating the Gini index that we invite students to use throughout the unit.

To our readers who are more familiar with the Gini index, we readily admit that such an approximation can significantly underestimate income inequality because, in effect, we are assuming that all households within a quintile have the same income. (Heuristically, this approximation fails to account for the inequality within quintiles). Farris (2010) provides a thorough analysis of the error associated with approximating the Gini index with a piecewise-linear Lorenz curve. He also provides two probabilistic (and illuminating) interpretations of the Gini index by viewing the derivative of the Lorenz curve as a probability density function. Jantzen 
and Volpert (2012) suggest a more sophisticated approach to approximating the Lorenz curve (and thus the Gini index) given quintile data. They exploit the selfsimilarity of the Lorenz curve to suggest a smooth form with only two parameters that yields a better approximation of the Gini index than even interpolation with a fifth degree polynomial (let alone a piecewise linear function!). The interested reader will find that both of these articles illustrate the complexity of the Gini index far more than we have attempted here. However, given our students, our course context, and our learning objectives, any in-depth discussion of error analysis or probability is beyond the scope of this paper.

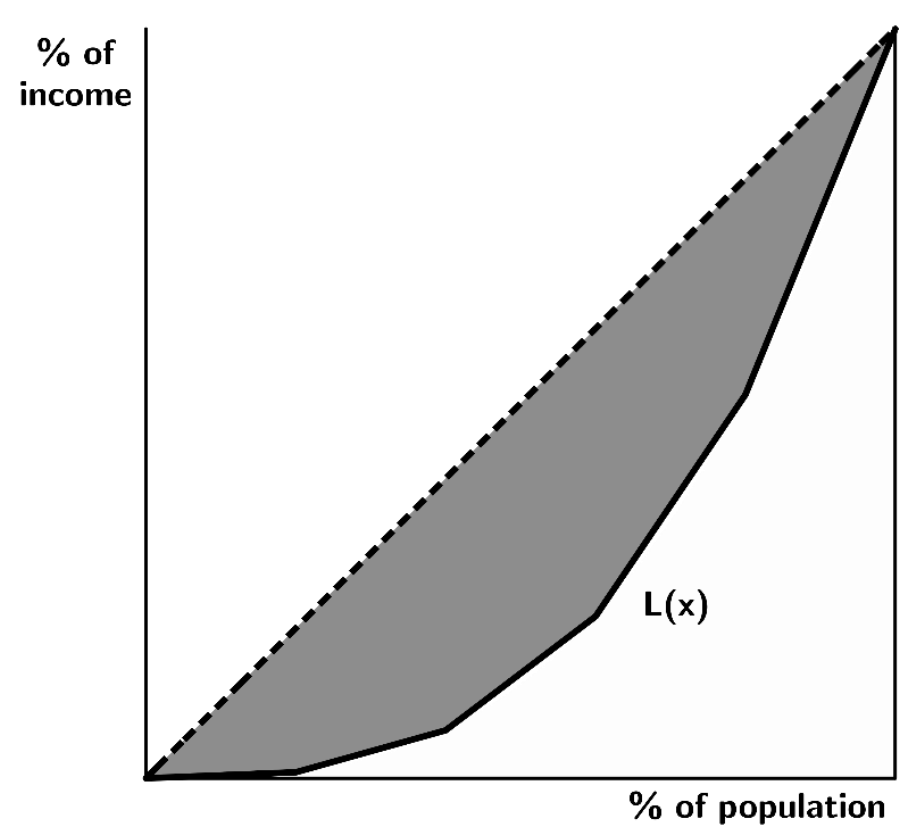

Figure 2. A Lorenz curve approximated by quintiles

We chose to feature the Gini index in our unit on income inequality for a variety of reasons. Most central to our motivation was our desire to forefront the concepts of ratio and percent. Constructing a Lorenz curve given an income distribution requires students to consider percentages within population and income as well as the interaction between the two. Specifically, given an income distribution, students must consider two separate part-to-whole ratios to construct and interpret phrases like "the poorest $20 \%$ of the population makes $5 \%$ of the income." Even our definition of the Gini index as a ratio of areas emphasizes the idea that relative size is often a more meaningful quantity than absolute size. We also chose to study the Gini index because it is one of the most common metrics of inequality, so data was readily available and easy to find (both for us as instructors and for our students). 
Finally, we were excited to introduce an idea as sophisticated and abstract as the Gini index in a course with developmental goals. In the fall 2015 semester, 74\% of freshmen in associate degree programs in the City University of New York (CUNY) system were placed into remedial mathematics (CUNY Task Force on Developmental Education 2016). Teaching mathematics for social justice has been shown to provide "a more compelling alternative to traditional remediation" by engaging students in work that is interesting and sophisticated while still providing students with exposure to basic mathematical concepts such as ratio (Rubel, HallWieckert, and Lim 2016, 567), or to push students to grapple with more advanced mathematical topics (Lim et al. 2015, Rubel et al. 2016). We viewed the Gini index as providing an opportunity to present students with advanced, college-level content in an accessible way.

\section{Lessons}

In this section, we describe our design of the Gini index unit. We implemented the unit in four thematic sessions each designed for a 90-minute class period. We start with a unit overview, which provides a bird's-eye view of the unit and shows how it addresses our two learning objectives. We then describe each lesson in detail, as well as the unit's culminating project, to both better illustrate how we addressed the objectives and provide readers with a clearer idea of how they could adapt the unit in their own classrooms. We note that the design of the unit is heavily contextualized to New York City, and we recommend that the necessary components of the unit be amended for use in institutions within a different context. (For some suggested amendments, please see "Suggestions and Resources for Instructors" below.) We also acknowledge that the following description is our intended implementation of the unit, but our actual implementation at Guttman deviated slightly at certain points due to natural classroom dynamics.

Unit Overview. The first three sessions provide students with an in-depth exploration of the Gini index and how it can be used to understand inequality. In the first session, students consider the concept of income inequality in a quintile distribution and are introduced to the Lorenz curve as a way to model income distributions through a physical simulation and an applet. The main outcomes of this session are that students construct a Lorenz curve given an income distribution and that students interpret what certain properties of the Lorenz curve say about the income distribution within a society.

To begin to concretize the abstract concept of the Lorenz curve, the second session introduces the Gini index associated with a Lorenz curve and invites students to explore income distributions and income inequality in New York City neighborhoods using census data. By the end of the second session, students should know how the Gini index is calculated given a Lorenz curve and they should be 
able to roughly discern the level of income inequality (as measured by the Gini index) within a population given the mean household incomes within quintiles.

The third session of the unit is the first to incorporate the City Seminar theme of immigration. Through a comparison of Guyana and the United States, students consider what it means for two countries with very different income distributions to have the same Gini index and what this reveals about the limitations of the Gini index as an indicator of the economic health of a country. Students then use the gross domestic product per capita based on purchasing power parity (PPP GDP) to construct possible mean household incomes within quintiles for the United States and Guyana.

The fourth session of the unit addresses our second learning objective by inviting students to explore the effects of three different fiscal policies on income inequality in the United States. After learning about progressive taxation, universal basic income, and guaranteed minimum income, students determine the effect of each policy on the income distribution and Gini index of the United States. By the end of this session, students should be able to decide which of the three policies best helps alleviate income inequality given the income distribution of any country.

The unit project brings together both of the learning objectives by drawing directly on the skills students have acquired throughout the unit. Students construct and interpret a possible income distribution for a country of their choosing given the PPP GDP and the Gini index. They then consider the effects of progressive taxation, universal basic income, and guaranteed minimum income on income inequality in the country to formulate their own perspectives about these policies.

Session 1: An Introduction to the Lorenz Curve. To introduce the topic of income inequality, the first session begins by presenting two distributions of $\$ 1,000,000$ dollars to five people (Fig. 3). Students are asked to identify which distribution they consider to be more equal and to try to quantify inequality within the distributions.

After fielding student responses to these prompts, the instructor moves toward introducing the term "quintile" and quantitative statements such as: "In Distribution A, the bottom $40 \%$ (or two quintiles) of the population receives $5 \%$ of the money." Reviewing various statements with this form prepares students for the Lorenz curve class simulation that follows.

The simulation begins with the teacher passing out index cards to students with different incomes. (Being a New York City-centric institution, we modeled the income distribution after Manhattan's). Students are instructed to group themselves into five quintiles based on their income, compute their quintile's mean income, and, once all mean incomes within quintiles are known, compute the percentage of the total class's income earned by their quintile. Students represent their quintile's share of the total income by cutting a paper meter strip to the corresponding length 
(e.g., $12 \%$ would be $12 \mathrm{~cm}$ ). Using these strips, the instructor guides the class through the construction of a Lorenz curve that models the class's income distribution.

Distribution A:

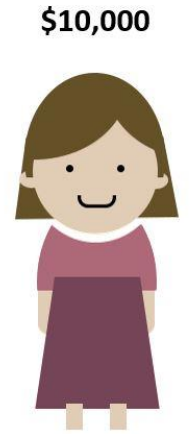

Distribution B:

$\$ 30,000$
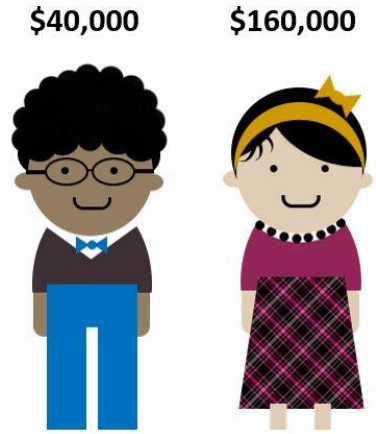

$\$ 270,000$

$\$ 520,000$

Figure 3. Two ways of distributing $\$ 1,000,000$ among five people

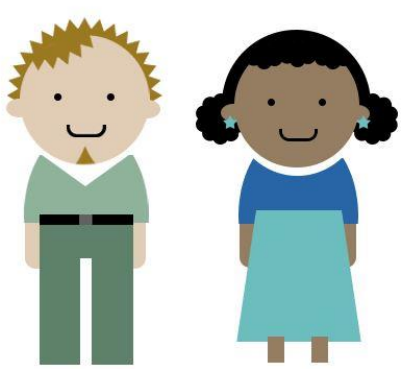

$\$ 580,000$

Referring back to the introductory discussion, the instructor makes clear that the points on the Lorenz curve reflect quantitative statements such as "The lowest earning $60 \%$ of the population make $21 \%$ of the income."

The final activity of this session asks students to use a GeoGebra applet ${ }^{2}$ we designed for the unit to come up with an income distribution with a particular level of inequality and construct a Lorenz curve for this distribution. The applet allows the user to set the mean incomes of quintiles for a population and then animates the construction of the associated Lorenz curve following the method used in class. Each of the five groups of students is assigned a different qualitative level of inequality - completely equal, close to equal, kind of equal, really unequal, or completely unequal - but students are encouraged to create their own distributions individually. Each student then draws their Lorenz curve and tapes it up on the class board, which is divided up into sections labeled with the levels of inequality.

The first session concludes with a class discussion comparing the students' Lorenz curves. Mathematically, this comparison should reveal the concept of the "line of equality" (from the completely equal group), and the qualitative idea that a more concave Lorenz curve reflects a more unequal income distribution. The class discussion can also include a discussion about the concept of income inequality, eliciting students' initial ideas about the relationship between income equality and fairness. The discussion should open up conversation to diverse perspectives about whether fairness necessarily means that everyone should have the same income and elicit ideas about factors that one might consider in evaluating fairness (e.g., education level and the nature of one's work).

\footnotetext{
${ }^{2}$ https://www.geogebra.org/m/sa7v2jg3. All GeoGebra applets are available for free use.
} 
Session 2: The Gini Index in New York City. Session two begins with students finding the area of two shaded regions on a grid (Fig. 4). At the end of the discussion, the teacher asks students to compare the areas of the two shaded regions in terms of ratios. More specifically, if the first shaded region is considered the "whole," students are asked to determine the percent of the whole that the second shaded region represents. This exercise provides students with a warm-up geometry problem with multiple points of entry while building a scaffold to introduce the formula for calculating the Gini index.

The class then reviews the key points from the concluding discussion from the previous day's activity-what a Lorenz curve looks like when there is complete income equality as well as complete income inequality and how greater concavity of the curve reflects greater income inequality. This review builds to the idea that the greater the area of the region between the line of equality and the Lorenz curve, the greater the inequality. In addition, the idea of maximum, or total, inequality is introduced, where the entire triangular region under the line of equality is encompassed between the line of equality and the Lorenz curve. Tying in the introductory activity of finding the ratio of areas, the teacher introduces the Gini index as a measure that quantifies inequality by taking the ratio of the area of the region between the line of inequality and the Lorenz curve to the area of the region at the maximum state of inequality.

1)

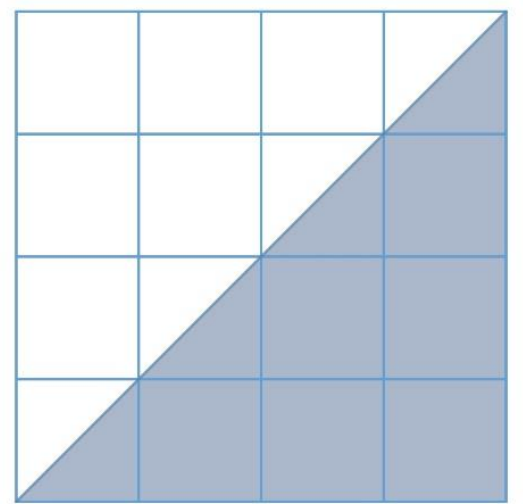

2)

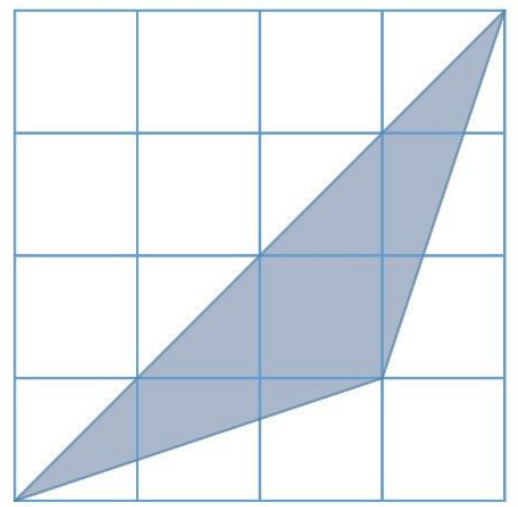

Figure 4. Shaded regions for area exercise

Having been introduced to the Gini index, the students are then instructed to tape up the Lorenz curves they drew in the previous session again but this time line them up in order from least to greatest amount of inequality. The students are then asked to find the Gini index of their distributions using a different GeoGebra applet, ${ }^{3}$ which has the additional function of providing the Gini index calculation

\footnotetext{
${ }^{3}$ https://www.geogebra.org/m/amzkxkqp
} 
for a distribution. The class concludes the activity by evaluating whether their Lorenz curves were in the correct order.

Session two ends with an "NYC inequality hunt" in which students look for inequality in income data from New York City neighborhoods. To preface the hunt, students are prompted to think about income inequality in the five boroughs of New York City - Bronx, Brooklyn, Manhattan, Queens, and Staten Island - and to use their prior knowledge about their city to predict which borough has the greatest and the least income inequality. Students are then given the mean household incomes within quintiles for each borough and are asked to refine their predictions based on the data (without explicitly calculating the Gini index). Finally, students use a Gini index calculator ${ }^{4}$ to test their predictions. This activity incites fruitful discussion about what characteristics of an income distribution translate to high or low Gini indices.

Having practiced how to spot income inequality (or equality) from an income distribution, students are given census data reporting the mean household incomes within quintiles for each New York City neighborhood and asked to use the Gini index calculator to find the neighborhoods with the greatest and least income inequality. In our implementation of the unit, we used Public Use Microdata Areas (PUMAs) as the geographical unit defining a New York City neighborhood, and we obtained the data using Social Explorer, ${ }^{5}$ a demographic data visualization and research tool. With over 50 PUMAs in New York City and only 10 minutes to complete their inequality hunt, groups did not have time to use a brute-force approach by computing Gini indices for each neighborhood. Instead, successful groups used both their knowledge of New York City neighborhoods and their sense of how an income distribution translates into a Gini index to choose candidate neighborhoods for which to compute the Gini index using the calculator. By sharing findings at the end of the session, students vocalize the strategies they used for choosing candidate neighborhoods.

Session 3: The Gini Index in the World. Session three begins by challenging students to consider what the Gini index of a country cannot tell us about the income distribution in that country. This challenge is guided by presenting students with the fact that both Guyana and the United States had a Gini index of 0.45 in $2007 .^{6}$ This comparison should lead to the crucial observation that the Gini index does not measure income, but income inequality. To emphasize this point further, the metric of gross domestic product per capita based on purchasing power parity ${ }^{7}$ is very

\footnotetext{
${ }^{4}$ https://www.geogebra.org/m/nscenwwr

${ }^{5} \mathrm{https}: / / \mathrm{www}$.socialexplorer.com

${ }^{6}$ https://www.cia.gov/library/publications/the-world-factbook/rankorder/2172rank.html

${ }^{7}$ PPP GDP per capita is a commonly used metric to gauge standard of living within a country.

Though not a measure of personal income, the PPP GDP per capita is a helpful approximation to
} 
briefly described and then suggested as a substitute for income per person within a country. Then, being presented with Guyana's 2007 PPP GDP of $\$ 5,000$ and the United States' of $\$ 48,000$, students can hopefully see the limitations of relying solely on the Gini index to reveal the economic health of a country.

Students are then asked to reverse engineer possible income distributions of the United States and Guyana given the PPP GDP and Gini index of each county. To achieve this, students make a sequence of guesses for the mean household incomes within quintiles, adjusting each guess to achieve the desired mean income and Gini index. For example, a student might initially guess that the mean household incomes within quintiles for the United States are $\$ 10,000, \$ 20,000$, $\$ 40,000, \$ 70,000$, and $\$ 100,000$. This would give a mean income of $\$ 48,000$ as desired, but the Gini index for this distribution is 0.38. To increase the Gini index, the student's second guess might concentrate more income in the higher quintiles at the expense of the lower quintiles. A table such as the one in Figure 5 can be used to help students organize their guesses (trials).

\begin{tabular}{|l|l|l|l|l|}
\hline & \multicolumn{5}{|c|}{ MEAN INCOMES } \\
\hline First quintile & TRIAL 1 & TRIAL 2 & TRIAL 3 & (TRIAL 4) \\
\hline Second quintile & & & & \\
\hline Third quintile & & & & \\
\hline Fourth quintile & & & & \\
\hline Fifth quintile & & & & \\
\hline SUM & & & & \\
\hline AVERAGE & & & & \\
\hline GINI INDEX & & & & \\
\hline
\end{tabular}

Figure 5. Table used to help students reverse engineer an income distribution

Once enough students reverse engineer income distributions for the United States and Guyana, the instructor can demonstrate that different income distributions can have the same Gini index to continue to illustrate the limitations of the Gini index. Students will also notice that the highest quintile in Guyana will have roughly the same income as the lowest quintile in the United States. This observation, among many others from comparing the income distributions, could lead to a discussion about "push-pull factors" for Guyanese immigrants to the United States.

personal income as it takes into consideration the national wealth of a country along with cost of living. 
Session 4: The Effects of Policy on the Gini Index and Wrap-Up. The first three sessions of the unit help students grow familiar with the tools of the Lorenz curve and the Gini index as measures of income inequality within a country. The fourth session invites students to put on a policymaker's hat by exploring the effects of different government policies on income inequality.

The fourth session begins by asking students to analyze the political cartoon "Let Them Eat Crumbs" (Darkow 2007). ${ }^{8}$ The cartoon depicts a large man eating half of a pie and leaving the other half for a crowd of people, to whom he exclaims, "Well I left you half! What are you, greedy?" Students consider what statement the cartoon is making, what mathematical ideas are behind this statement, and whether or not they agree with the statement.

To support the statement of the cartoon, the instructor then shares data with the class that reveal the various forms of fiscal inequality in the United States. This data should at least include the mean household incomes within quintiles, but can also include data on wealth inequality (as opposed to income inequality) and data comparing US CEO salaries to employee salaries. The point of sharing this data is to set up the big question of the day: "What are some policies that the United States could use to try to tackle income inequality head on?"

To answer this question, the instructor introduces policies of progressive taxation, universal basic income, and guaranteed minimum income. As a brief review of these policies for the unfamiliar reader, a progressive tax system taxes higher-earning individuals at a higher rate, universal basic income is a policy whereby all citizens annually receive a certain amount of money from the government, and guaranteed minimum income is a policy whereby all citizens earning below a certain threshold are annually given an amount of money to meet that threshold. The progressive tax system is introduced as a policy already in place in the United States, while the universal basic income policy is introduced to students through relevant news articles about recent events related to it. Having sufficiently established the foundations of the three policies, the instructor sets reasonable parameters for the three policies (i.e., the tax rates for each income quintile and the amounts of universal basic income and guaranteed minimum income) and asks students to explore each policy's effect on the Gini index in the United States. The table in Figure 6 can be used to help students organize their analysis of the three policies.

\footnotetext{
${ }^{8} \mathrm{https}: / /$ caglecartoons.com/viewimage.asp?ID=\%7B A6545529-A612-419D-B009-
} $\underline{47449 \mathrm{C} 49 \mathrm{~A} 6 \mathrm{~EB} \% 7 \mathrm{D}}$ 


\begin{tabular}{|l|l|l|l|l|}
\hline & $\begin{array}{l}\text { Mean income } \\
\text { before policies }\end{array}$ & $\begin{array}{l}\text { Mean income with } \\
\text { guaranteed minimum } \\
\text { income of }\end{array}$ & $\begin{array}{l}\text { Mean income after } \\
\text { adding universal basic } \\
\text { income of }\end{array}$ & $\begin{array}{l}\text { Mean income } \\
\text { after progressive } \\
\text { taxes }\end{array}$ \\
\hline First quintile & $\$ 25,000$ & & & \\
\hline Second quintile & $\$ 47,000$ & & & \\
\hline Third quintile & $\$ 70,000$ & & & \\
\hline Fourth quintile & $\$ 104,000$ & & & \\
\hline Fifth quintile & $\$ 265,000$ & & & \\
\hline SUM & $\$ 511,000$ & & & \\
\hline AVERAGE & & & & \\
\hline GINI INDEX & & & & \\
\hline
\end{tabular}

Figure 6. Table used to help students analyze policy effects on the Gini index

Unit project description. The unit culminates with a final project that asks students to apply their understanding of the unit to study income inequality within a particular country. The first of two parts of the project requires students to choose a country (not the United States) and research that country's Gini index and PPP GDP. Using this data, students construct a possible income distribution and draw a Lorenz curve for this distribution. Students then use these metrics to compare their chosen country to the United States and describe what an immigrant from their country to the United States might experience in light of the comparison. All of these findings and reflections are summarized in a few paragraphs of writing that include a table of the quintile incomes and a figure of the Lorenz curve.

Part two of the project mirrors session four in that students use their income distributions from part one to analyze the effects of progressive taxes, universal basic income, and guaranteed minimum income on income inequality. Because each student will have different distributions, the parameters for the three policies need to be defined more generally than they were in session four. For example, we set the threshold for the guaranteed minimum income to be $50 \%$ of the country's PPP GDP and the universal basic income to be $25 \%$ of the country's PPP GDP. For the progressive tax policy, we set the tax rates within the quintiles to be $3 \%, 8 \%$, $13 \%, 17 \%$, and $22 \%$. Having analyzed the effects of the three policies on their income distributions, students are asked to write a paragraph explaining which policy reduced income inequality the most, which reduced income inequality the least, and why they think some policies were more effective than other policies. Students finish the second part of the project by writing about other factors to consider (besides just the Gini index) when evaluating the three policies and describing, with justification, what policy they would choose to implement in their country. 


\section{Pedagogical Rationale}

\section{Pedagogical Framework: Culturally Relevant Mathematics Pedagogy}

Our pedagogical rationale in designing the unit was influenced by both our goals as educators in general and our goals for this unit in particular. At the heart of our approach is an effort to uphold culturally relevant pedagogy as it applies to mathematics education. Culturally relevant pedagogy is a framework centered on three goals for students: academic success, cultural competence, and critical consciousness (Ladson-Billings 1995a, 1995b). Ladson-Billings defines academic success as "the intellectual growth that students experience as a result of classroom instruction and learning experiences" (Ladson-Billings 2014, 75). This growth is not limited to acquiring skills as outlined by standardized testing or other external standards; instead, it encompasses the development of students' "literacy, numeracy, technological, social, and political skills in order to be active participants in a democracy" (Ladson-Billings 1995a, 160). Cultural competence is having the opportunity to draw on and connect to one's culture and experiences as a legitimate, valid source of knowledge to support learning. Ladson-Billings (2014) states that attaining cultural competence results in students being able to "celebrate their cultures of origin while gaining knowledge of and fluency in at least one other culture"-namely, the dominant culture (75). Finally, critical, or sociopolitical, consciousness is "the ability to take learning beyond the confines of the classroom using school knowledge and skills to identify, analyze, and solve real-world problems" (Ladson-Billings 2014, 75). More specifically, Ladson-Billings describes the need to prepare students for "active citizenship" by empowering them with the knowledge and skills "to critique the cultural norms, values, mores, and institutions that produce and maintain social inequities" (Ladson-Billings 1995a, 162). Applied to mathematics education, culturally relevant pedagogy seeks to center students' learning of mathematics on their lived experiences, including the conditions of inequity and oppression they might face, to prepare them for democratic citizenship (Tate 1994).

Rubel and Chu (2012) offer an explicit framework for culturally relevant mathematics pedagogy specifically, or CureMap. The framework consists of three dimensions that further expound on each of the goals of culturally relevant pedagogy to research-based ideas in mathematics education. The first dimension is teaching mathematics for understanding. Rubel and Chu draw on the work of Hiebert and Carpenter (1992) to suggest a view of academic success in mathematics as going beyond attaining procedural knowledge of mathematics towards understanding concepts (Hiebert and Grouws 2007) and sense-making (Wenger 1998). The second dimension is centering instruction on students' experiences. 
Rubel and Chu (2012) draw on the work of Moll et al. (1992) to argue for the importance of drawing on students" "funds of knowledge" (133). In other words, cultural competence in terms of mathematics education means valuing students' knowledge and experiences as members of communities and cultures outside of the classroom as connected and central to the learning that takes place in the classroom. Furthermore, Rubel and Chu (2012) include students' experiences as learners in the classroom in the definition of students' experiences. According to their framework, in addition to connecting to students' identities outside of the classroom, culturally relevant mathematics pedagogy means that students must be "central participants in the building of mathematical understanding" (Rubel and Chu 2012, 41).

Finally, the third dimension of CureMap is developing students' critical consciousness with and about mathematics. For this dimension, Rubel and Chu (2012) refer to the literature on teaching mathematics for social justice. Founded on Paulo Freire's critical pedagogy ([1968] 2007), teaching mathematics for social justice is fundamentally about what Gutstein (2006) calls "reading the world with mathematics" (24), or using mathematics to critique the status quo; and "writing the world with mathematics" (26), which refers to using mathematics to change it. Developing students' critical consciousness with mathematics means empowering them with the ability to wield their mathematical knowledge and skills as a tool, or a "weapon," to critique and challenge hegemonic practices and conditions in society (Gutstein 2012). Second, Rubel and Chu also include the importance of developing students' critical consciousness about mathematics, which requires that students turn their critical skills back on mathematics itself to understand it as a human tool that has also played a role in creating or maintaining hegemonic conditions.

The learning objectives described above are tied to our pedagogical framework. Our goals for students to be able to use a quantitative lens to describe and analyze inequality as well as to evaluate policies stem from our overall goals for students to achieve a conceptual understanding of mathematics, to make connections to and draw on their lives and their world, and to be empowered to read and write the world with mathematics. In what follows, we elaborate on how the lessons more specifically address these three goals.

\section{Teaching Mathematics for Understanding}

Because the Gini index is based on ratios, the unit provides multiple opportunities for students to engage in developing a conceptual understanding of ratio. The Gini index unit also consists of activities that engage students in sense-making that are not specifically tied to pre-determined mathematical content.

Developing Conceptual Understanding of Ratio and Other Topics. There are two ways that ratio and proportion come into play in the calculation of the Gini 
index. First, the Lorenz curve is a model of income distribution based on proportions-the percentage of income that is made by a cumulative percentage of the population. Second, the calculation of the Gini index is itself a ratio: the area of the space between the line of equality and the Lorenz curve and the area representing absolute inequality, which is what yields an index value between 0 and 1. These two ideas present multiple opportunities for students to engage with the concepts of ratio and proportion, as they have to consider how different levels of incomes could yield similar Gini indices and to understand what a Gini index represents.

The idea that the ratio of the income values rather than their absolute values determines the value of the Gini index is reinforced at multiple points in the unit. In the first session, when students participate in building a Lorenz curve using an income distribution simulation with their classmates, the activity requires students to convert their income values to percentages. The final product of the simulation is a graph whose axes both represent ratios in terms of percentages: the percent of the population ( $x$-axis) and the percent of society's income ( $y$-axis). This idea is physically experienced by students representing their quintile group's income using a part of a meter strip, which represents $100 \%$ of society's income. Thus, even before being introduced to the Gini index itself, students are exposed to the idea of the model of income distribution being entirely based on proportions.

In the final activity of the first session, students create their own income distributions and Lorenz curves based on an assigned level of inequality. Having students work individually yields multiple Lorenz curves with similar levels of inequality in each group even though the absolute amount of the incomes may be entirely different. The most obvious example of this is in the case of completely equal distribution, in which case every quintile would have the same mean income; regardless of how high or low the chosen income, it would qualify as a completely equal distribution and result in a Lorenz curve that coincided with the line of equality. The second session reinforces the proportional nature of the Lorenz curve and the Gini index, as students calculate Gini indices using the applet and find that distributions with varying levels of income yield similar indices. The third session then directly asks students to consider how two countries with very different economic situations-the United States and Guyana-can have the same Gini index, thus further reinforcing the idea that the Gini index is based on relative quantities as opposed to absolute ones.

The idea of the Gini index representing a ratio of two areas is addressed in the second session. As an abstract geometric quantity, the area between the line of equality and the Lorenz curve is a rather meaningless number without some touchstone values with which to compare. For example, it is difficult to interpret an area between curves of 0.2 as "big" or "small" without reference to the largest possible value this area can be. Thus, considering the ratio of the area between 
curves to the area under the line of inequality reinforces proportional reasoning by considering the question "compared to what?" The reader will observe that the area under the line of equality is always equal to 0.5 and is independent of the Lorenz curve, so that effectively the Gini index is simply twice the area between curves. A classroom discussion of this fact would not be without value, especially if initiated by students' observations, but we chose not to define the Gini index as twice the area between curves because this definition could seem rather arbitrary without justification. (E.g., one might wonder why the Gini index is not defined as three times the area between curves).

Engaging in Sense-Making Practices. The Gini index unit also provides students with opportunities for engaging in sense-making practices. Although sense-making is embedded throughout most of the activities of the unit, there are two activities where it is central, as students do not need to rely on specific mathematical concepts or approaches to be successful. One of these activities is the NYC inequality scavenger hunt. There are no rules or instructions for how students should go about determining which neighborhoods' quintile distributions represent high or low levels of inequality. Instead, the activity invites students to come up with strategies that are reasonable given their understanding of how the Gini index is measured and calculated. Another activity relying on student sense-making is performing trials to come up with a distribution that matches a country's given Gini index. There are no instructions to students for how they should adjust their distributions in subsequent trials; here, too, students have to come up with their own strategies for making adjustments that would help them achieve their goal and avoid a completely randomized process. These two activities rely on students applying their understanding of how the Gini index works and its relationship to inequality in a distribution to make reasonable decisions.

\section{Centering Instruction on Students' Experiences}

There are three main ways that instruction is centered on students' experiences. First, the Gini index is a social tool that is inherently tied to the real world. In this unit, it is used to provide a lens for understanding immigration as well as evaluating real world policies about income inequality. For students for whom immigration, income inequality, and injustice is important, the Gini index unit has the potential to hold personal significance. Second, throughout the unit, instruction is designed to draw on students" "funds of knowledge" (Moll et al. 1992) to make meaning in their process of learning. Finally, in conjunction with drawing on students' funds of knowledge, the unit positions students as producers of knowledge in their experiences in the classroom. 
Relevance of the Gini Index Unit. Unlike more general mathematical concepts such as ratio or percent, the Gini index as a measure of inequality is inherently a socially relevant tool, given more legitimacy by its use by the World Bank and other organizations. The social significance of the broader topic of income inequality is further contextualized by its ties to the topic of immigration and fiscal policies. Immigration is a topic that has the potential to be relevant for many students, particularly in New York City, where the foreign-born population is nearly 37\% (United States Census Bureau 2016). The unit project opens up opportunities for students to make personal connections to their learning, as they are asked to choose the countries they want to study.

The policy considerations are also grounded in reality rather than presented as abstract ideas. The progressive tax rates that students are instructed to use in their assignment are modeled after the United States federal income tax rates. Guaranteed minimum income and universal basic income are introduced to students through relevant news articles (Weissman 2013; Dillow and Rainwater 2017). Universal basic income was particularly topical at the time of the unit's implementation, as nations such as Finland had been experimenting with some form of it (Goodman 2016), and leaders in technology within the United States had also expressed their support and launched pilot programs (Dillow and Rainwater 2017). Based on these current events, we set the guaranteed minimum and universal basic income rates similar to ones being used in the world. Thus, the unit presents an opportunity for students to evaluate the effectiveness of real world policies and add their voice to relevant and current conversations.

Drawing on Student Funds of Knowledge. Even if students do not view the Gini index and the context in which it is presented as personally relevant, there are still opportunities for students to draw on their own lives and experiences in class activities and assignments. For two of the main activities in the unit, students' experiences as New Yorkers play a key role. As described earlier, the income inequality scavenger hunt in New York City neighborhoods relies on students' sense of how the Gini index measures inequality but could also be supported by students' sense about where they see inequality in their city (e.g., neighborhoods where housing projects are down the street from luxury condominiums). Students' experiences in New York City are also key in comparing the United States and Guyana to discuss implications related to immigration. Although the Guyanese foreign-born population only constitutes about $4.5 \%$ of all foreign-born people in New York City, it is a significant population; in 2016, the Guyanese foreign-born (immigrant) population in New York City was 140,341, nearly half of the 271,544 Guyanese immigrants in the entire United States (United States Census Bureau 2016). The activity draws on the unique role of the Guyanese immigrant population 
in New York City and invites students to draw on their potential and particular experiences as New Yorkers.

The unit also draws on students' prior understanding and sense about inequality and injustice. Prior to any instruction about the Gini index, the unit starts with asking students to articulate their own ideas for comparing the levels of inequality in two income distributions. The activity provides students with the opportunity to apply any mathematical skills and approaches that are already in their arsenal, such as analyzing the differences between incomes in the distributions, the differences in the incomes between the two distributions, or the ranges of the distributions, with their own perspectives and prior understandings about what constitutes inequality influencing their choice of approach. Students' knowledge and perspectives about inequality are also incorporated into their unit projects. The Gini index provides a value but is not accompanied by any guide for deciding what level of inequality is acceptable. Students have to apply their own judgments, based on their opinions and experiences, to ultimately make interpretations and form conclusions about whether they feel a certain level of inequality is reasonable or unjust.

Students' knowledge and perspectives about the real world are also included in the policy considerations. Although the resulting Gini index from the three policy applications are meant to inform students' final policy recommendations, students are also asked to consider factors beyond the index that they believe to be important. The Gini index is presented as one tool that can help analyze policy, but it is stressed that it is the students' use, interpretation, and considerations of this tool in context that should ultimately drive conclusions about their analyses.

Positioning Students as Central in Building Mathematical Understanding. The lessons also center instruction on students' experiences by positioning students as active participants in constructing mathematical ideas. In the first session, the students physically create a Lorenz curve using a distribution in the class as their first introduction before seeing a digital simulation and model. At the end of that first session, when students are assigned a level of inequality for creating a distribution, the students create and evaluate their own distributions rather than being shown examples of distributions with different levels of inequality.

Similarly, both in the third session and in their Gini index unit projects, the students are asked to come up with distributions given a set of parameters. There is no prescribed answer for what the final outcome should be aside from meeting the parameters. As explained previously in the section about teaching mathematics for understanding through sense-making, the students generate strategies and ideas for raising or lowering the Gini index in their distributions. In all of these cases, the students are positioned as being able to contribute and produce knowledge that aids in their own and their classmates' learning and understanding of the Gini index, 
income inequality, and the mathematical or quantitative ideas on which they are based.

\section{Developing Critical Consciousness about and with Mathematics}

Developing Critical Consciousness with Mathematics. The Gini index unit challenges students to measure and critically analyze income inequality in society. Throughout the unit, students have opportunities to consider the levels of income inequality in their own city and nation. In these lessons, students consider not just the mean incomes of the quintiles but the percentages and cumulative percentages of the incomes attributed to the lower quintiles in comparison to the upper quintiles. Intuitive concepts of justice and fairness are not explicitly taught, and the determination of what constitutes a reasonable disparity compared to an unjust disparity is left to the students to determine. However, seeing that the first quintile in Manhattan earns just $1.4 \%$ of the total income while the fifth quintile earns $62 \%$ has the potential to illustrate the magnitude of the inequality. It is in the fourth session, when the political cartoon is introduced along with data about the various forms of fiscal inequality in the United States, when students are asked to consider fairness. For some of these data (e.g., ratios comparing employee salaries vs. CEO salaries), the data for the United States is presented alongside data for other countries. Making comparisons highlights how great the disparities are in the United States while simultaneously showing the possibility for incomes to be distributed more evenly, pushing students to consider whether the United States has a just system. Evaluating policies can also have this effect. Using the Gini index to measure the potential for different policies to reduce income inequality brings out the idea that social conditions can be changed.

The Gini index unit also presents opportunities for students to consider ideas about justice and inequality on a theoretical level. In the first and second sessions, the income distributions that students create for the various levels of inequality serve as concrete examples for students to reflect on as they form their own conceptions about the relationship between income inequality and unfairness. In particular, reflecting on distributions that show absolute equality (everyone has the same income) and maximum inequality (one person has all the income) can push students to think critically about what income inequality might mean at these extreme levels. For example, students might consider whether it is fair for everyone to have the same income or if there are factors that justify that some receive more income than others. These considerations can therefore inform more nuanced critical judgments that do not automatically equate fairness with total equality without deeper consideration. Thus, while the evidence highlighting the magnitude of income inequality in Manhattan and in the United States provides a motivation to question the fairness of the social conditions in these places, students must utilize 
their mathematical skills in a critical way to make their own judgments and arguments about fairness.

In their unit projects, students have an opportunity to put forth a conclusion about fairness and injustice as it relates to the income distribution in their chosen country. For the project, students are asked not only to employ their mathematical skills to better understand the country's level of income inequality but also to critically evaluate whether the country's income inequality is reasonable or unjust and to consider how different policies could address income inequality in the country. In other words, the Gini index provides students with one way to measure inequality, empowering them with information to make potential arguments about injustices in the world and how to address them.

Developing Critical Consciousness about Mathematics. The Gini index unit also shows students that the Gini index is a human tool for measuring income inequality. This encourages students to be critical of mathematics itself and to challenge the association of mathematics with correctness and universality, which can often lead to hegemonic practices. Recall that the introduction of the Gini index unit has students come up with their own ways to evaluate inequality; one of the purposes of this activity is to situate the Gini index among a plethora of valid approaches, each with their strengths and weaknesses. Furthermore, in the third session, having students come up with their own possible income distributions for the Gini indices of the United States and Guyana serves the purpose of illustrating the limits of the Gini index, as it is unable to represent one definite income distribution but instead represents a multitude of possibilities with the same measure. This limitation can hide important and relevant information about justice and injustice as it relates to income distributions. For example, it is possible to assign an income of zero to one or more quintiles in a distribution, which can prompt a discussion about the fundamental differences between a society where entire quintiles have no income and a society where all people have income, even if these societies have the same Gini index.

\section{Reflections: Opportunities and Challenges}

The previous section highlights our pedagogical rationale based on the CureMap framework. In this section, we provide insights and reflections on the opportunities and challenges we encountered based on our experience teaching it and student feedback we received in the form of verbal comments and an end-of-semester reflective assignment. We write this section with the intent that it will aid us in making revisions for future implementation and provide helpful considerations for others looking to adapt our unit. As in the previous section, we draw on the CureMap framework to organize our reflections. 


\section{Reflections on Teaching Mathematics for Understanding}

As we discussed in our pedagogical rationale, the Gini index unit we designed provided a plethora of opportunities for students to engage with the concept of ratio and in general sense-making practices. Furthermore, the emphasis on sense-making provided an opportunity for unexpected and rich engagement with ratio for some students. In particular, we observed this engagement in the activity in the third session, where students came up with distributions that matched the mean incomes and Gini indices for the United States and Guyana. The task was intended for students to find and use the sum of the five quintiles as a parameter for coming up with income distribution trials. Whether because they had missed the instructions or misunderstood their task, some students came up with distributions that had correct Gini indices but the wrong sums. In two instances in which this occurred and the instructor pointed out the students' errors, rather than beginning again, the students calculated the percentage of the total income in the distribution that each of their income values represented, and then used those percentages to find a proportionally equivalent distribution that had the correct sum. The instructor noted in their reflections that in both of those instances, the students seemed proud of their creative solutions to their dilemmas.

The sense-making opportunities provided in the unit were also noted directly by the comments of one student. While working on the income trial activity, the student expressed to the instructor that they were enjoying engaging in what they referred to as problem solving. This student had been less consistent in completing assignments outside of class; however, they completed the Gini index project and mentioned to the instructor as they turned it in that they worked harder on this than on prior assignments.

It is unclear, however, how well students understood the fundamental role of ratio in the construction of the Gini index. In students' projects, for example, where they were asked to explain how the piecewise Lorenz curve relates to their country's Gini index, very few students articulated the notion that the Gini index represented the ratio of two areas. The instructor also noted that when she brought up this absence in students' projects, most of the students expressed confusion about the concept. In retrospect, the idea of the Gini index representing a ratio of two areas as addressed in the second session was inadequately reinforced and represents a weakness in our unit. Although the instructor explained how the Gini index is calculated using the ratio of two areas, students never had to find these areas and their ratios themselves. Instead, we had students compute Gini indices using an applet to avoid having students spending all of their energy performing cumbersome area calculations. As a result, students may have seen the Gini index calculation as a mysterious process taking place inside of a black box and outside of themselves. In addition, the concept of the Gini index as measuring the ratio of 
two areas is perhaps the most abstract concept that was introduced to them and therefore less readily understood or accessible to students, especially given the lack of reinforcement.

\section{Reflections on Centering Instruction on Students' Experiences}

The inherent social and political relevance of the Gini index in the world has the potential to be important to some students, though it may simultaneously be too abstract and distant to the realities of others. One student expressed a personal connection in reflecting on their unit project:

My grandfather is from Ireland, and that's why I chose Ireland to see the contrast if I was still living there now, if I was born there instead of born in America. And I saw it was much better living in America than it is in Ireland, because we probably would have been in the bottom quintile, we'd probably only be making like four grand a year, compared to a lot more than that here. So quality of life would have went up for me here than there. So personally I get to actually see the difference of how my grandfather lived when he was a kid then how he would have lived over here.

Another student, who constantly vocalized an interest in international affairs during class, said that the Gini index gave them insights about foreign countries. Reflecting on their unit project, which was about Iran, they wondered about the standard of living of Iranians within the lowest quintile. Even though this student did not make personal connections to their own life, their personal interest in the topic prompted them to ask questions and attempt to make meaning of their analysis.

The Gini index unit did not have equal appeal to all the students, however. The two students mentioned above who related the Gini index to their personal lives and interests voluntarily engaged in conversation with the authors about their experiences with the unit and are not likely to be representative of the larger student population. In fact, looking at submission rates of the unit project for the Gini index unit tells a different story. Each of the course's unit projects required a draft submission before a final submission. On the draft due date, students were asked to submit their work, regardless of its level of completion, so that they could receive feedback on what they had so far. There were $45 \mathrm{draft}$ and/or final assignment submissions for the Gini unit project, in contrast to 56 for each of the other units' projects in the semester. The confusion about how the Gini index is calculated along with the general abstractness of the Gini index may have been daunting for some students, as many did not even submit a draft for initial feedback. Despite some students' perspective of the Gini index as a valuable tool, it is possible that others were less engaged with the unit because they felt less personal interest or connection to it.

Yet another factor that may have contributed to students' greater reluctance to complete the Gini index assignment was that despite introducing the Gini index as 
a way to measure income inequality among a range of options that students came up with, we did not re-engage students' ideas or compare them with the Gini index as valid approaches for analyzing inequality. In other words, we did not make strong connections between students' prior conceptions of inequality and the new measure we presented. When designing the introductory activity where students compare inequality in two distributions, we had anticipated that students' approaches would be limited to approaches that would only take the two ends of the distribution into account, such as the range or the ratio of the top and bottom incomes. A discussion of these approaches would motivate an approach that considered how income was distributed within the range; we envisioned that the Gini index would thus build on and extend student thinking about measures of inequality. Instead, some students came up with their own inventive ways to compare the income distributions. For example, one student considered how each person (representing a quintile) in the distribution would fare by switching from one distribution to another. Although the student was given space to share this approach during the introductory activity, the approach was never reconsidered in comparison to the Gini index or re-engaged in any other way in subsequent lessons. As a result, the Gini index unit did not sufficiently build on and connect with students' prior understanding with regard to understanding and measuring inequality.

\section{Reflections on Developing Critical Consciousness with and about Mathematics}

The most salient strength of the Gini index unit was its contribution to students' sense that mathematics can play a powerful role in changing the world by uncovering and addressing inequality. The Gini index as a tool provided students with a unique opportunity to simulate the effects of policies aimed at reducing inequality in income distributions and measure the effectiveness of these policies. In other words, the Gini index made it possible for students to experience immediate feedback that concretized the ability for policies to result in measurable change.

At the end of the semester, the instructor assigned students a final course reflection assignment, for which students were asked to reflect on the course's class sessions, activities, and assignments that they felt contributed to their opinions about three statements: 1) Mathematics is universal and culture free; 2) I think mathematics has played a powerful role in shaping our world; and 3) I think mathematics can play a powerful role in changing our world. A tally of student responses on the final course reflection assignment revealed that of the four units in the course, the Gini index unit was most frequently named as contributing to students' thinking about the power of mathematics to change the world. Out of 37 total references to units or coursework in relation to this idea, 21 of them named 
the Gini index unit. Of these 21 instances, 7 of them specifically described the Gini index as a tool that empowers people to uncover injustices so that they can be addressed. For example, one student wrote, "Rather than using this mathematical system of calculating the inequality of income just to see the income distribution, we can use it to see how off our economic society is and use it as a way to better it."

The piece of the unit that had the most impact on the development of students' critical consciousness, however, was performing policy evaluations. Nearly half of the responses about the Gini index unit contributing to their ideas of mathematics making change (10 out of 21) included a reference to policy, and an additional two responses referred generally to the idea that cities or governments can make decisions about income distribution. These students linked the mathematical analysis of policies to the ability to change the world. For example, one student wrote, "It will change our world, seeing what is benefitting the people and what is not, and seeing if the numbers are becoming more equal over time and if not the policies will be adjusted and changed." Another student went further in articulating that not only can policy be used to address problems with income inequality, but also that income inequality is a problem created through policy: "So, since the US created the income inequality and policies to try make income distribution more equal. They have the power to change the numbers to create a better society for the US people in these unequal economic classes." This student saw policy not only as a useful means to react to inequality, but as a powerful tool that shapes and creates unequal systems. Their observation reveals a deep understanding that inequality is a systemic and constructed state, as opposed to a naturally imperfect one that can be improved. It is unknown if they already held this perspective about systemic inequality prior to their experiences with the Gini index unit, but at the very least the unit helped them sharpen and support their ideas.

Most of the responses about policy referred to nations, cities, or their governments as the bodies creating or implementing policies. However, there was one student who referred to their own role in effecting change. More specifically, they saw the act of evaluating the policies through their assignment as the vehicle for them to make an impact:

In addition, I also learned how we can use mathematics and contemplate different [applications of] policies that decrease the level [of] income inequality. In addition, in this assignment math served as a tool to create a plan to make a better society. In this case, math helped as a powerful tool for changing the world because other individuals can learn from my assignment and observe how we can create equity in society.

On the other hand, developing critical consciousness about mathematics was a weak point of the unit. Despite engaging students in activities that were supposed to illuminate some of the weaknesses of the Gini index as a measure of inequality, we did not sufficiently present alternatives for students to consider, including 
making explicit connections and comparisons between the Gini index and other measures of inequality, including the students' own approaches for evaluating inequality. Making these connections could have highlighted how and whether the Gini index reflects the experienced realities of populations and strengthened students' critical considerations of the Gini index as a human tool with limitations.

\section{Conclusion: Suggestions and Resources for Instructors}

In our concluding section, we discuss suggestions and resources for future implementations of our curricular unit. We have two objectives in offering our suggestions, which we address in their own subsections. First, we hope that our reflection on the unit provides helpful insights for improving its design, both for others looking to use the unit in their classrooms as well as for our own future implementations. The first subsection thus offers suggestions based on the opportunities and challenges we discussed in our reflection. Second, we acknowledge that the unit we have described in this paper is designed specifically for our context, including our setting and student population. The second subsection provides suggestions for modifications that will aid in adapting the unit to other contexts.

\section{Addressing Challenges and Extending Opportunities}

The Gini index presents a unique and valuable opportunity to engage students with a sophisticated tool that supports thinking about inequality in society as well as to support the development of fundamental mathematical concepts and quantitative literacy skills. In order to ensure access to all students, however, stronger connections to students' prior mathematical and experiential knowledge need to be established. One suggestion is to establish a better connection between the Gini index and the approaches that students came up with to assess income inequality in the first session's introductory activity. In subsequent lessons, when students have a better understanding of how the Gini index measures inequality, students' approaches could be revisited and compared with the Gini index to draw connections, address misconceptions, and build on students' prior knowledge.

Comparing students' approaches to assessing income inequality with the approach of the Gini index not only better supports student learning, but it also supports students to be critical about mathematics as they evaluate the strengths and weaknesses of the Gini index in relation to other measures of inequality. Consequently, students can be positioned more squarely in the center of their learning with the role and power to critically assess their world and to critically assess knowledge, rather than allowing the mathematical knowledge to hold power 
over them. In addition, the Gini index itself should be more directly analyzed in terms of how it might relate to social conditions. For example, some questions that were not addressed include whether higher (or lower) Gini indices are associated with social variables such as levels of crime, health, economic stability, and social mobility. Further exploration into these relationships might provide more information to help students better interpret Gini indices and to develop their awareness about statistical tools in general.

A significant weakness that emerged about the unit was that there were insufficient opportunities for students to understand the Gini index as a ratio of areas. To address this weakness, a session could be added where students engage in more substantial and direct activity measuring the areas under piecewise Lorenz curves and finding their ratios. One suggestion is to extend the introductory activity for the second session, where students estimate areas using a grid and find their ratios. Students could be given various piecewise Lorenz curves with grid overlays to measure and analyze. An alternative suggestion comes from the work of Catalano et al. (2009). Their article focuses on teaching the Gini index in a calculus course, but they offer alternative suggestions for estimating areas without requiring calculus. One suggestion is to create a triangle with approximately the same area as the region of inequality resulting from the Lorenz curve. The vertices of this triangle are $(0,0),(1,1)$, and a point along the $x$-axis (Fig. 7). The student would visually estimate the point along the $x$-axis that would result in the creation of a triangle with approximately the same area as the region of inequality.

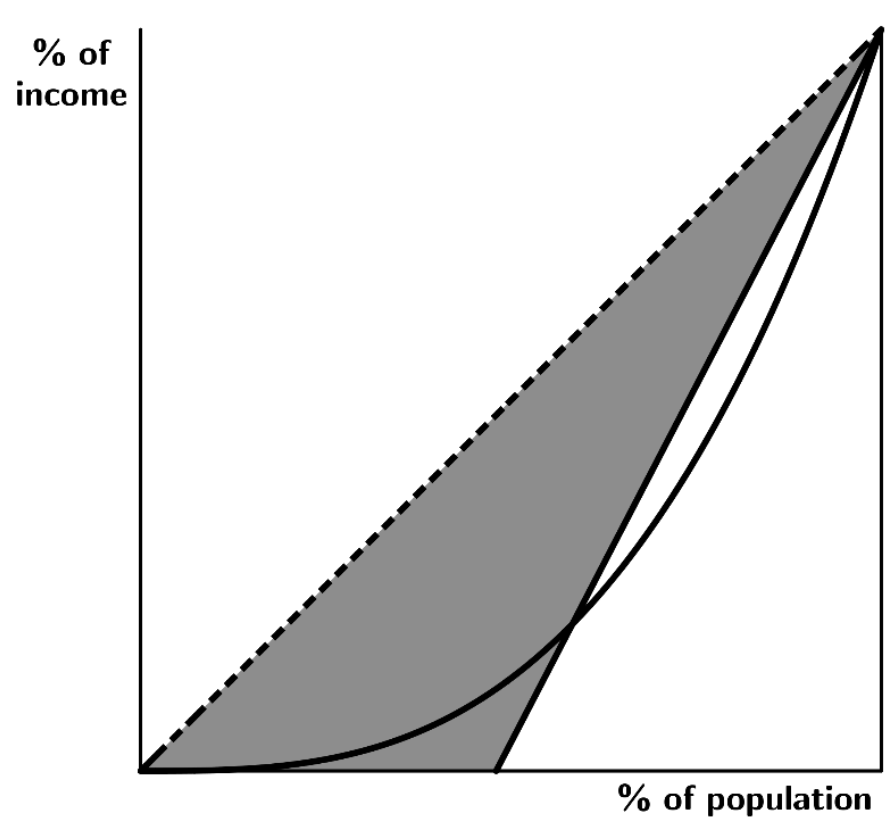

Figure 7. Catalano et al.'s triangle method for estimating the Gini index 
After calculating the area of the region of inequality, students could directly perform the subsequent ratio calculation of the area of the region of inequality to the total potential area (0.5). These approaches reinforce how the Gini index is measured while not overwhelming students with tedious area calculations. In addition, these approaches provide further opportunities for students to draw on estimation and sense-making skills that are valuable in a quantitative reasoning course.

Strengths of the Gini index unit could also be better leveraged to engage all students in rich learning opportunities. The two students who came up with a creative solution to scale an incorrect distribution with the correct Gini index experienced memorable moments that reflected and solidified their understanding of the role of ratio in the Gini index. The unit could provide explicit scaffolding opportunities for all students to experience such a moment in their problem solving, or at the very least the opportunity to grapple with the idea of proportional distributions and their Gini indices. One suggestion would be to present students with the situation that the two students found themselves in; the instructor could give students a distribution with the desired Gini index but not the desired mean income. Another suggestion to elicit this idea is to present students with various distributions, some of which have income values that are in proportion to each other. Students would have to determine which distributions have the same Gini index or explain why distributions that are proportional distributions have the same Gini index.

\section{Adapting the Unit to New Contexts}

Our unit was implemented in a Quantitative Reasoning course, and as such, we catered the unit to focus on the concepts of ratio and percent. There are plenty of opportunities to address learning outcomes in other mathematics courses through a study of the Gini index. The applications to calculus are clear (trapezoidal rule, areas between functions, interpretation of the derivative of the Lorenz curve, etc.), and are already addressed in Catalano et al. (2009). Here, we mention some applications in other math courses.

- Instructors who are teaching a college algebra or pre-calculus course could consider having students determine the piecewise linear function given quintiles. This would address learning outcomes such as constructing piecewise functions, interpreting the slope of a line, and finding the equation of a line through two points.

- Pre-calculus instructors could give students a particular form of the Lorenz curve with stated parameters as in Farris (2010) and use statistical software to find the least-squares regression from given quintiles. This could help students see functions as members of families, and could provide for a robust modeling project.

- Polynomial interpolation of quintile data points is a nice application of solving linear systems of equations in a linear algebra course. 
As we mentioned previously, Guttman's location in Midtown Manhattan heavily influences the content of its courses - Guttman views New York City as its campus and laboratory, and Guttman instructors shape their class activities and projects accordingly. Two places in our unit that demonstrate this principle are the income simulation in session 1 (which used an income distribution that mirrored Manhattan's) and the NYC inequality hunt in session 2.

For instructors looking to adapt the simulation and inequality hunt, we suggest an appropriately modified income distribution and/or data set that mirrors one of many possible populations. For example, Social Explorer has data on income quintiles for census tracts, counties, and states. Additionally, instructors could make use of public employee salary databases to model an income distribution based on the population of public employees within a city, county, or state. Sports teams also provide player salaries, and a simulation of inequality hunt could be centered on the sports teams of a particular league. (E.g., which professional baseball team is most equitable in its payment of players?) One could also use a country's GDP as a representative of that country's income and have students simulate the income distribution of a particular collection of countries (e.g., African countries). In effect, one can anthropomorphize a country to be a person within a population of countries. For the inequality hunt, students could use the GDP of various countries to investigate which continent has the highest level of inequality among its constituent countries.

Finally, as mentioned earlier, the Gini index can measure inequality in the distribution of any quantifiable resource, not just income. For a non-standard resource distributed to the population of the world's countries, consider the quantification of happiness in the World Happiness Report. ${ }^{9}$ Another creative resource that can be studied on the county or state levels is opportunity via the Opportunity Index. ${ }^{10} \mathrm{We}$ encourage instructors to consider a study of the Gini index applied to a variety of resource distributions within various populations.

\section{Acknowledgements}

We would like to acknowledge Dr. Dave Kung and Dr. Lily Khadjavi for inspiring the first author's foray into teaching mathematics for social justice. In particular, the idea to build a curricular unit around the Gini index started with a lesson Dr. Kung shared with the first author. The GeoGebra applets developed for the Gini index unit were inspired by the masterful applets of our colleague, Forest Fisher. The guest editors of this issue along with the reviewers of our initial manuscript provided very helpful insights and comments that led to a much-improved article. We would also like to thank and acknowledge our students for sharing their

\footnotetext{
${ }^{9} \mathrm{http}: / /$ worldhappiness.report/ed/2018/

${ }^{10}$ https://opportunityindex.org/
} 
reflections and wisdom with us that allows us, in turn, to reflect on our work. Their voices are what matter and what ultimately motivate us to do this work.

\section{References}

Catalano, Michael T., Tanya L. Leise, and Thomas J. Pfaff. 2009. “Measuring Resource Inequality: The Gini Coefficient." Numeracy 2(2): Article 4. https://doi.org/10.5038/1936-4660.2.2.4.

CUNY Task Force on Developmental Education. 2016. Report of the CUNY Task Force on Developmental Education.

http://www2.cuny.edu/about/administration/offices/undergraduatestudies/developmental-education/.

Darkow, John. 2007. "Let Them Eat Crumbs." Cartoon. Cagle Cartoons, April 6, 2007. https://www.caglecartoons.com/viewimage.asp? $\mathrm{ID}=\{\mathrm{A} 6545529$ A612-419D-B009-47449C49A6EB\}.

Dillow, Clay and Brooks Rainwater. 2017. "Why Free Money for Everyone Is Silicon Valley's Next Big Idea." Fortune, June 29, 2017.

Farris, Frank A. "The Gini Index and Measures of Inequality." The American Mathematical Monthly 117(10) 85-164. https://doi.org/10.4169/000298910x523344.

Freire, Paulo. (1968) 2007. Pedagogy of the Oppressed (30 ${ }^{\text {th }}$ Anniversary Edition). New York: Continuum.

Gini, Corrado. 1912. Variabilità E Mutabilità: Contributo Allo Studio Delle Distribuzioni E Delle Relazioni Statistiche. [Fasc. I.]. Tipogr. Di P. Cuppini.

Goodman, Peter S. 2016. "Free Cash in Finland. Must be Jobless." New York Times, December 17, 2016. https://www.nytimes.com/2016/12/17/business/economy/universal-basicincome-finland.html.

Gutstein, Eric. 2006. Reading and Writing the World with Mathematics: Toward a Pedagogy for Social Justice. New York, NY: Routledge.

Gutstein, Eric. 2012. "Mathematics as a Weapon in the Struggle." In Opening the Cage, edited by Ole Skovsmose \& Brian Greer, 23-48. Boston: Sense Publishers. https://doi.org/10.1007/978-94-6091-808-7_2.

Hiebert, James and Douglas A. Grouws. 2007. "The Effects of Classroom Mathematics Teaching on Students' Learning." In Second Handbook of Research on Mathematics Teaching and Learning, edited by Frank K. Lester Jr., 371-404. Charlotte: Information Age Publishing.

Hiebert, James and Thomas P. Carpenter. 1992. "Learning and Teaching with Understanding." In Handbook of Research on Mathematics Teaching and Learning, edited by Douglas A. Grouws, 65-97. Reston: National Council of Teachers of Mathematics. 
Jantzen, Robert T. and Klaus Volpert. 2012. "On the Mathematics of Income Inequality: Splitting the Gini Index in Two." The American Mathematical Monthly 119(10): 824-37. https://doi.org/10.4169/amer.math.monthly.119.10.824.

Ladson-Billings, Gloria. 1995a. "But That's Just Good Teaching! The Case for Culturally Relevant Pedagogy.” Theory into Practice 34(3): 159-165. https://doi.org/10.1080/00405849509543675.

Ladson-Billings, Gloria. 1995b. "Toward a Theory of Culturally Relevant Pedagogy." American Educational Research Journal 32(3): 465-491. https://doi.org/10.2307/1163320.

Ladson-Billings, Gloria. 2014. "Culturally Relevant Pedagogy 2.0: a.k.a. the Remix." Harvard Educational Review 84(1): 74-84. https://doi.org/10.17763/haer.84.1.p2rj131485484751.

Lim, Vivian, Erica Deahl, Laurie Rubel, and Sarah Williams. 2015. "Local Lotto: Mathematics and Mobile Technology to Study the Lottery." In Cases on Technology Integration in Mathematics Education, edited by Drew Polly, 43-67. Hershey: IGI Global. https://doi.org/10.4018/978-1-4666-6497$\underline{5 . \operatorname{ch} 003 .}$.

Moll, Luis C., Cathy Amanti, Deborah Neff, and Norma Gonzalez. 1992. "Funds of Knowledge for Teaching: Using a Qualitative Approach to Connect Homes and Classrooms." Theory Into Practice 31(2): 132-141. https://doi.org/10.1080/00405849209543534.

Rubel, Laurie H., and Haiwen Chu. 2012. "Reinscribing Urban: Teaching High School Mathematics in Low Income, Urban Communities of Color." Journal of Mathematics Teacher Education 15(1): 39-52. https://doi.org/10.007/s10857-011-9200-1.

Rubel, Laurie H., Maren Hall-Wieckert, and Vivian Y. Lim. 2016. "Teaching Mathematics for Spatial Justice: Beyond a Victory Narrative." Harvard Educational Review 86(4): 556-579. https://doi.org/10.17763/1943-5045$\underline{86.4 .556 .}$.

Rubel, Laurie H., Vivian Y. Lim, Maren Hall-Wieckert, and Mathew Sullivan. 2016. "Teaching Mathematics for Spatial Justice: An Investigation of the Lottery." Cognition and Instruction 32(1): 1-26. https://doi.org/10.1080/07370008.2015.1118691.

Tate, William F. 1994. "Race, Retrenchment, and the Reform of School Mathematics." Phi Delta Kappan 75(6): 477-480, 482-484.

United States Census Bureau. 2016. "Foreign-Born Population: Americas: Latin America: South America: Guyana.” 2016 American Community Survey (5Year Estimate). U.S. Census Bureau's American Community Survey Office. 
Numeracy, Vol. 12 [2019], Iss. 1, Art. 5

Wenger, Etienne. 1998. Communities of Practice: Learning, Meaning, and Identity. New York: Cambridge University Press. https://doi.org/10.1017/CBO9780511803932.

Weissman, Jordan. 2013. "Martin Luther King's Economic Dream: A Guaranteed Income for All Americans." Atlantic, August 28, 2013. 